УДК 316

$10.17213 / 2075-2067-2020-6-136-143$

\title{
ЭКСПЕРТНАЯ ОЦЕНКА СОЦИАЛЬНОЙ СПРАВЕДЛИВОСТИ В КОНТЕКСТЕ ИНТЕГРАЦИИ ЭТНИЧЕСКИХ ОБЩНОСТЕЙ КРАСНОДАРСКОГО КРАЯ
}

\section{(C) 2020 г. Н. И. Чернобровкина}

\section{Южнный федеральный университет, г. Ростов-на-Дону, Россия}

Цель исследования - рассмотреть социальную справедливость как принџии регуляциии межсэтнических взаимодействий и основу сочиальной интеграции в Краснодарском крае.

Методологическая база исследования. В рамках реализации проекта по Программе фундаментальных и прикладных научных исследований по теме «Этнокультурное многообразие российского общества и укрепление общероссийской идентичности» осенью 2020 года было проведено сочиологическое исследование понимания и интерпретации справедливости применительно к сфере межэтнических отношений в Краснодарском крае. Методологическим основанием инструментария являлись идеи конструктивистской теории этничности и теории социальной справедливости. Справедливость рассматривалась как терминальная и инструментальная иенность, регулирующая межэтнические отнотения и обеспечивающая интеграџию этнических общностей в регионе.

Результаты исследования. На основе позиции экспертов были выявлены факторы, формирующие ощущение сочиальной справедливости/несправедливости у представителей этнических общностей - шапсугов, армян, турок-месхетинцев, а также казаков. Это позволило определить степень влияния представлений о сочиальной справедливости на характер ожиданий и ограничений при формировании общегражданской идентичности этих представителей этнических общностей. В результате было выяснено, что последующая интеграчия этнических общностей Краснодарского края предполагает не обособленную помощь с предоставлением особого политического статуса и экономических льгот, а признание равенства гражданских прав их представителей как россиян при содействии сохранения культурной самобытности.

Ключевые слова: сочиальная справедливость; межэтнические отночения; этнические общности; соџиальная интеграџия; принщип равенства.

\section{EXPERT ASSESSMENT \\ OF SOCIAL JUSTICE IN THE CONTEXT OF INTEGRATION OF ETHNIC COMMUNITIES OF THE KRASNODAR REGION}

\section{(C) 2020 N. I. Chernobrovkina}

Southern Federal University, Rostov-on-Don, Russia

1 Статья подготовлена в рамках выполнения Программы фундаментальных и прикладных научных исследований по теме «Этнокультурное многообразие российского общества и укрепление общероссийской идентичности» 2020-2022 гг. по проекту «Социальная справедливость в обеспечении гармонизации межэтнических отношений и укреплении общероссийской идентичности населения на Юге России» (Соглашение №075-02-20202172 от 25.08.2020 г., внутренний номер ДГП0708/20-01РГ). 
The purpose of the research is to consider social justice as a principle of regulation of interethnic interactions and the basis of social integration in the Krasnodar territory.

Methodological base of the research. As part of the project under the Program of Fundamental and Applied Scientific Research on the topic "Ethnocultural Diversity of Russian Society and Strengthening the All-Russian Identity" in the fall of 2020, a sociological study was conducted on the understanding and interpretation of justice in relation to the sphere of interethnic relations in the Krasnodar Territory. The methodological basis of the toolkit was the ideas of the constructivist theory of ethnicity and the theory of social justice. Justice was viewed as a terminal and instrumental value that regulates interethnic relations and ensures the integration of ethnic communities in the region.

Results of the research. On the basis of the experts' position, factors were identified that form a sense of social justice/injustice among representatives of ethnic communities - Shapsugs, Armenians, Meskhetian Turks and also Cossacks. This made it possible to determine the degree of influence of ideas of social justice on the nature of expectations and restrictions in the formation of the general civil identity of these representatives of ethnic communities. As a result, it was found that the subsequent integration of ethnic communities in the Krasnodar Region does not presuppose separate assistance with the provision of special political status and economic benefits, but the recognition of the equality of civil rights of their representatives as Russians, while promoting the preservation of cultural identity.

Key words: social justice; interethnic relations; ethnic communities; social integration; the principle of equality.

Введение. С 90-х годов Краснодарский край занимал активную позицию в процессе конструирования региональной идентичности. Это обусловлено полиэтничным составом населения региона, включающего значительное большинство русских (более $85 \%$ ), армян, украинцев, белорусов, татар, грузин, адыгейцев, немцев, турок-месхетинцев и др. В ходе переписи населения 2010 г. казаки учитываются как отдельная национальность. Выступая на заседании рады Кубанского казачьего войска, «казаки заявили, что никогда не скрывали своей этнической принадлежности, ни во времена политических репрессий, ни в годы гражданской войны, и не намерены этого делать и сейчас» [1]. Армяне, проживающие на Кубани, выразили опасение, что их численность может быть занижена, хотя они являются самой многочисленной этнической общностью в регионе после русских. Основанием для подобных утверждений послужил опрос во время переписи, который проходил некорректно. В частности, «были случаи, когда армянам с окончанием фамилии на “-ов" типа "Хачатуров" и "Саркисов” вопрос о национальной принадлеж- ности задавался в следующем виде: "Вы русские?”, а вопрос о родном языке: “Ваш родной язык - русский?"» [1].

В отношении малых народов, проживающих на территории края, возникли проблемы с их идентификацией: «Все зависит от того, к какой этнической группе себя причислят сами представители этносов, - отмечал политолог М. В. Савва. - В первую очередь это относится к туркам-месхетинцам, которые всегда испытывали трудности в вопросах самоидентификации» [1]. Это вызвано тем, что турки-месхетинцы определяют свою идентичность как отличительную от материнского этноса в силу уникальной «исторической судьбы». Подобные сложности возникают и с шапсугами, которые по законодательству являются коренным народом, проживающим на своей исторической родине. Часть представителей этой этнической общности идентифицируют себя с адыгами, другие признают частью этого этноса, а третьи - как самостоятельный народ.

Каждая из этнических общностей Краснодарского края претендует на утверждение коллективного права своего народа как 
высшую ценность, которая в соответствии с принципом справедливости предполагает обеспечение равных условий для реализации прав каждого индивида. Справедливость в массовых и индивидуальных представлениях ассоциируется с равенством возможностей, равным доступом к общественным благам. Применительно к сфере межэтнических отношений ее часто рассматривают как равенство народов, этнических общностей и групп [2]. С другой стороны, справедливость характеризуют как регулятор социальных отношений, базовое ценностное основание любого общества, как инструмент достижения согласия между различными социальными группами [3]. Поскольку характер межэтнических отношений в регионах Юга России вариативен, то он может исследоваться в зависимости от конкретной ситуации, субъектов и исторически сложившейся устойчивой модели их взаимодействий в контексте форм организации жизни этнических общностей, определяющих различную интерпретацию справедливости/несправедливости.

В рамках реализации проекта по Программе фундаментальных и прикладных научных исследований по теме «Этнокультурное многообразие российского общества и укрепление общероссийской идентичности» осенью 2020 г. было проведено социологическое исследование понимания и интерпретации справедливости применительно к сфере межэтнических отношений в Краснодарском крае. Исследование имело поисковый характер, включающий сбор эмпирического материала методом фокус-группового интервью и серии глубинных экспертных интервью. Участниками фокус-группы были председатели краснодарских краевых общественных организаций различных этнических общностей: казаков, армян, адыгов, греков, азербайджанцев, чеченцев, осетин, абхазов. В качестве экспертов выступили сотрудники административных и силовых учреждений, научные работники, занимающиеся анализом межэтнических отношений в Краснодарском крае, публицисты и активисты различных этнических общностей армян, турок-месхетинцев, шапсугов. Инструментарий глубинного и группового интервью разрабатывался с учетом выявления представлений о социальной справедливости как принципа регуляции межэтнических взаимодействий и основы социальной интеграции этнических общностей в Краснодарском крае. Сбор материала был ориентирован на установление современных или исторических событий, которые актуализируют этническую идентичность, обусловливают интерпретацию этих событий в категориях справедливости/несправедливости. Методологическим основанием инструментария являлись идеи конструктивистской теории этничности и теории социальной справедливости. Справедливость рассматривалась как терминальная и инструментальная ценность, регулирующая межэтнические отношения и обеспечивающая интеграцию этнических общностей в регионе.

Результаты исследования. Смысловые единицы понимания справедливости.

Справедливость правового статуса казачества. С 90-х гг. Краснодарский край занимал активную позицию в процессе конструирования региональной идентичности. Региональные элиты края выражали идею державного консерватизма с опорой на казачество. Как отмечает эксперт, «это было вызвано низким уровнем урбанизации населения края, преобладанием сельского хозяйства как определяющей отрасли хозяйственного развития региона. Но противостояния с федеральной элитой никогда не было, идеи консерватизма были ориентированы на местное население. И с начала 2000 г. губернатор Краснодарского края А.Н. Ткачев уже позиционировал себя как менеджер, выражающий интересы федерального центра».

Вопросам реабилитации казачества уделялось большое внимание в 90-е гг. ХХ века. «Правительство региона выделяло дополнительное финансирование казакам, - констатирует представитель научного сообщества. - Казаки были выделены в отдельную структуру, они не рассматриваются как составная часть этносферы края. Специально существует отдельная административная структура, которая в правительстве края занимается казачеством. Они получают финансирование из бюджета края и по специальной федеральной программе. В сельских поселениях им предоставлены льготные условия землепользования. В целом они сейчас выступают 
не как общественная организация, а как полувоенизированная структура - опора власти». Однако сами казаки считают несправедливым последствия реабилитации: «Не произошло возврата частных земель и не было восстановлено казачье самоуправление».

Ситуация включения казачества в события по присоединению Крыма показала, что казаков можно использовать как определенную опору для решения вопросов государства, при которых не могут быть использованы официальные силовые государственные структуры. Если ранее основной функцией казачества было поддержание общественного порядка, то впоследствии она расширилась. «Государство финансово поддерживает казачьи военные корпуса и соответствующие общественные организации, — констатирует представитель администрации края. - Большое количество казаков занимается охранной деятельностью, которая легализована законодательством края».

Сейчас казачество имеет статус не столько общественной организации, сколько бюрократической и полувоенизированной структуры с финансированием из регионального бюджета, что признается несправедливым по отношению к другим представителям этнических общностей и всех жителей края. «В Краснодарском крае проживает примерно 150 тыс. казаков. Но население края - 5млн., - считает общественный деятель. - Почему все должны себя идентифицировать с казачеством? Многие примыкают к казакам, чтобы трудоустроиться. Казаки получили возможность заниматься охраной правопорядка за зарплату. Поэтому хочешь работать в этой сфере - записывайся в казаки. То же касается ЧОПов - организаций по охране. Казаки вне тендеров получили право заниматься на платной основе охраной организаций, магазинов, школ». Эксперты отмечают, что «неприязнь к казакам проявляется в крупных городах и на черноморском побережье, но в степной части края отношение позитивное, поскольку оно выступает коллективным субъектом, который осуществляет хозяйственную деятельность (очистка озера, ремонт школы, охрана рынка). Для них характерен высокий уровень самоорганизации».

Справедливость интеграции коренного малочисленного народа. Приоритет прав казачества признается шапсугами несправедли- вым. Имея статус коренного малочисленного народа, они стремились к расширению своих политических, экономических и культурных прав. «Они хотели своего представительства в органах власти - общественном Совете - в соответствии с аналогичным правом малочисленных народов, как народов Севера и Дальнего Востока», - отмечает представитель органов власти. Однако в настоящее время они уже не претендуют на участие в общекраевом управлении в силу малочисленности и снижения авторитета их общественной организации среди самих шапсугов и окружения.

Несправедливым признается шапсугами отсутствие поддержки развития их традиционных видов хозяйствования и решение проблемы с землепользованием. «У шапсугов нет крупных хозяйств, хотя они надеялись на поддержку развития их традиционных видов хозяйствования - пчеловодства, выращивания фундука, - констатирует научный работник. - Но проблемы связаны с проблемами землепользования и федеральной собственности лесного фонда, возможности деятельности в котором ограничены. Шапсуги стремились к расширению своих экономических прав с использованием статуса коренного народа, но это им не удалось». Однако сами шапсуги считают, что «многие земли оказались в руках предпринимателей, которые запустили все сельхозугодья, выставив на продажу под коттеджную застройку гектары плодородных сочинских земель».

Инфраструктура сельских поселений шапсугов обновляется очень медленно и не столько в интересах населения, сколько в интересах, например, компаний, осуществляющих газификацию населенных пунктов. Однако рост туристического бизнеса позволяет шапсугам получать прибыль. «Они специализируются на туризме, - отмечает сотрудник администрации края. — Уже открыто 7 учреждений, которые торгуют товарами народного промысла, продуктами питания, вовлекают в труд, связанный с национальной идентичностью. Инфраструктуру обеспечили региональные органы власти». Однако в целом это не решает проблему трудовой занятости на селе, и молодежь признает это место жительства малоперспективным. «Близость туристических центров, - подчеркивает эксперт, - демонстрирующих другой уровень 
жизни, только обостряет чувство несправедливости. Это обстоятельство также способствует миграции молодежи в мегаполисы, откуда они уже не возвращаются».

Несправедливость признается по линии исторической памяти. Шапсуги считают, что Кавказская война - это травма, поскольку на этой территории жило большое количество адыгов, а в настоящее время менее 30 тыс. «Они особенно болезненно воспринимают, когда устанавливают мемориальные знаки тем, кто покорял Кавказ, кто покорял побережье и кто участвовал в резне адыгов, - говорит представитель органов власти. - Поэтому мы особенно внимательно контролируем установление подобных “знаков”». При поддержке представителей черкесской организации, апеллируя к последствиям кавказской войны, они требуют отдельную программу поддержки помощи шапсугов для охраны их традиционного образа жизни.

Проблема с изучением родного языка признается первоочередной. «На сегодняшний день ситуация такова, что родной язык изучается в школах аулов Большой Кичмай, Хаджико, Агуй-Шапсуг и Псебе, - отмечает представитель общественной организации. - Но и в этих школах изучение родного языка не организовано в необходимом объеме. Хотя в этих школах обучается свыше $70 \%$ детей-адыгов, которые практически никак не охвачены изучением родного языка». Представители администрации края, наоборот, отмечают, что «2 млн. в год выделяется по линии национальной политики на развитие национального языка, культурные центры, развитие прессы шапсугов. Они сами мало ориентированы на серьезное изучение своего языка, относятся к этому как к формальности, и поэтому все держится на энтузиастах». Эксперты с ними солидарны, поскольку, по их мнению, «начинает теряться самоидентификация народа: в семьях мало разговаривают на языке, плохо читают, хотя в настоящее время все условия создаются (приобретение учебников и оборудования, обучение преподавателей - 20 человек повышали квалификацию в Майкопе), но адыгский изучается как второй иностранный; в школах не все хотят его изучать».

Справедливость экономической интеграции армян. Активная экономическая деятельность армянской общности сопровождалась постепенной адаптацией к ней жителей региона, лояльность которых была вызвана следующими обстоятельствами.

Во-первых, эксперты полагают, что с 90-хгг. «напряжение в отношениях с местным населением снизилось после признания Армении в качестве стратегического партнера России, и выступать против армян означало занимать антигосударственную позицию». Кроме того, согласно позиции представителей научного сообщества, которые в своих суждениях опираются на данные социологических исследований, взаимной адаптации армян и местных жителей способствовало «сравнение их с другими диаспорами - чеченцами, дагестанцами. В этом смысле армяне - созидатели и ментально близки».

Во-вторых, армяне не стремятся к политическому представительству в краевых органах власти. «Они являются преимущественно главами поселений и не стремятся к представительству в органах власти, - отмечает представитель органов власти. - Армяне оказывают влияние на политическую власть через бизнес, их всего 6\% населения края, и они лоббируют свои интересы на уровне муниципалитетов».

В-третьих, их экономическая деятельность способствует развитию региона и определяет высокую конкуренцию внутри самой общности. «Мы не наблюдаем консолидации внутри армянской общности, хотя организаций, представляющих ее интересы, много, говорит один из экспертов. - Это вызвано жесткой экономической конкуренцией между ее представителями и лидерами, а также длительностью проживания армян на территории края, дисперсным расселением и миграцией из различных стран. Ее сохранение вызвано наличием армянско-апостольской церкви, вокруг которой и осуществляется консолидация армян. Ее культурная миссия - поддержание армянской идентичности».

Bce вышеперечисленные обстоятельства признаются справедливыми населением Краснодарского края. Однако ксенофобские стереотипы по отношению к армянам сохраняются у жителей края, что признается представителями этой этнической общности несправедливым. Примером является бизнесмен С. Н. Галицкий, который сменил свою 
армянскую фамилию, чтобы не провоцировать ксенофобские настроения и стереотипы, при этом он очень много делает для благоустройства края.

Справедливость правовой интеграции мурок-месхетинцев. Переселение турокмесхетинцев в 80-х гг. в Краснодарский край сопровождалось негативным отношением местного населения к их образу и стилю жизни, вероисповеданию, культурной замкнутости. Сами турки-месхетинцы отмечают негативное к ним отношение с первых недель пребывания на Кубани: «Когда мы сюда приехали, Кондратенко еще правил. Я сама лично слышала, как он выступал по телевизору и говорил: “Турки-месхетинцы переступят только через мой труп, чтобы здесь жить"». Как отмечали представители органов власти и силовых структур, причиной острых конфликтных ситуаций были сексуальные преступления.

Противоправное поведение, нарушение условий природопользования при осуществлении сельскохозяйственной деятельности и неконструктивное поведение национально настроенных лидеров с требованием преференций обеспечило признание справедливости дискриминационных действий региональных органов власти и казаков в 90-е гг. ХХ века. «Краевые власти воспринимали пребывание турок-месхетинцев как временное, - отмечает представитель научного сообщества. Кроме того, они вселились в дома уехавших в Крым татар. Это были “ручные сделки", которые не имели официальной регистрации». «Их активные лидеры предпринимали попытки выхода на международный уровень, поскольку у них сложилась с 60-х гг. практика отстаивания своих прав, которая была чужда органам власти и краснодарским лидерам общественных организаций, - констатирует представитель органов власти. - Лидеры были национально настроены и не конструктивны, что создавало конфликтную ситуацию. Кроме того, они нарушали условия природопользования при осуществлении видов деятельности».

Препятствия в получении гражданства и проживания на территории региона, ограничение возможностей экономического развития расценивалось самими турками как несправедливое. У представителей органов власти иное мнение: «Они скопились в районах стратегического назначения, где прописка была запрещена. Они хотели получать паспорта не индивидуально, а всей общиной». Местные жители были недовольны тем, что «они получили высокие выплаты и поехали туда, куда им захотелось, и не хотят регистрироваться». Все эти обстоятельства и постоянные конфликты с казаками спровоцировали их массовое и добровольное переселение в 2005-2006 гг. в США по программе, реализуемой Международной организацией по миграции. Несмотря на то, что выехало более 13 тысяч турок-месхетинцев, часть из них осталось: «У меня четыре сына, все отслужили в Российской армии, отец Кубань защищал в войну, победу встретил в Берлине. Я терпеть не могу американский образ жизни, а также и саму Америку».

Оставшимся на территории края представителям этнической общности был предоставлено гражданство. «После отъезда представителей диаспоры в США туркам здесь удалось легализовать свой гражданский статус, - отмечает эксперт. - Несколько лет назад предпринималась попытка создания общественной организации, которая хотела войти в Центр национальных культур». Однако турки-месхетинцы считают несправедливым сохранение к ним радикального отношения местного населения, препятствие властей развитию их религиозной жизни, отсутствие закона о реабилитации данного народа. В частности, по их мнению, «местные власти не уделяют достаточного внимания религиозным потребностям ахыска, часто препятствуют развитию их религиозной жизни, запрещают открывать мечети или молельные дома. Священнослужители сами находятся в уязвимом положении и не могут действовать активно».

В настоящее время фактором конфликтности может стать ослабление межпоколенческих связей и контроля со стороны этнической общности за молодыми людьми, увлекающихся «истинным исламом». По мнению экспертов, старшее поколение способно удержать молодежь от радикализма путем обращения к исторической памяти: «В годы войны мы, как и другие народы страны, сражались на фронтах Великой Отечественной войны, среди нас есть 
Герои Советского Союза, полные кавалеры ордена Славы, тысячи месхетинцев погибли на фронтах сражений».

Таким образом, к факторам, которые рассматриваются представителями этнообщностей и жителями края как несправедливые, относятся: правовой статус и финансирование из регионального бюджета казачьих общественных организаций; проблемы с изучением родного языка, землепользования и трудовой занятости шапсугов; ксенофобские стереотипы и предвзятое отношение к армянам, активно участвующим в экономическом развитии региона; сохранение радикальных настроений в отношении турок-месхетинцев и препятствие развитию их религиозной жизни. Эти факторы затрудняют формирование общероссийской идентичности.

Заключение. Реализация принципа справедливости в регулировании межэтнических отношений предполагает признание равенства гражданских прав представителей этнических общностей как россиян. На это ориентирована национальная политика в регионе, которая предполагает, во-первых, конструирование российской нации, то есть увеличение количества людей, которые считают себя гражданами России, во-вторых, минимизацию этнических конфликтов и, в-третьих, обеспечение межэтнического согласия.

Обеспечение межэтнического согласия в Краснодарском крае осуществляется при взаимодействии федеральных с региональными и муниципальными органами власти, этническими НПО, Центром национальных культур края и активными представителями этнической общности.

Проект интеграции этнических общностей Краснодарского края предполагает не обособленную помощь с предоставлением особого политического статуса и экономических льгот, а признание равенства гражданских прав их представителей как россиян при содействии сохранения культурной самобытности.

Реализация такого проекта будет признана справедливой населением края в случае, если будут проведены следующие мероприятия:

- выравнивание правового статуса казачества как общественной организации и финансирования его деятельности из соответствующих федеральных и региональных программ;

- осуществление дальнейшей поддержки и финансирования преподавания родного языка шапсугов, обеспечение инфраструктурой сельских поселений и помощь в создании хозяйств, специализирующихся на туризме;

- создание благоприятного психологического климата для инвестиционной деятельности армян при поддержке средств массовой информации и интернет-сетей;

- развитие отношений с общественными организациями турок-месхетинцев и их лидерами, сохранение исторической памяти о действиях старшего поколения в годы Великой Отечественной войны и его пропаганда среди молодежи.

\section{Литература}

1. Перепись населения отразит этнический состав Краснодарского края. Сайт «Кавказский узел» [Электронный ресурс]. — Peжим доступа: https://www.kavkaz-uzel.eu/ articles/175954/.

2. Попова И.П. Социальная справедливость в научных дискуссиях 1990-2010-х годов // Мир России. - 2016. - №3. - С. 56-75.

3. Файзулин Ф.С., Файзулин Т.Ф. Социальная справедливость как принцип стабилизации межнациональных отношений в обществе // Гуманитарные, социально-экономические и общественные науки. - 2014. №11-1. - С. 73-77.

\section{References}

1. Perepis' naseleniya otrazit etnicheskiy sostav Krasnodarskogo kraya. Sayt «Kavkazskiy uzel». [The population census will reflect the ethnic composition of the Krasnodar Territory] [Elektronnyy resurs]. — URL: https://www. kavkaz-uzel.eu/articles/175954/.

2. Popova I. P. Sotsial'naya spravedlivost' v nauchnykh diskussiyakh 1990-2010-kh godov [Social Justice in Scientific Discussions of the 1990-2010s] // Mir Rossii [World of Russia]. 2016. — №3. - Pp. 56-75.

3. Fayzulin F.S., Fayzulin T.F. Sotsial'naya spravedlivost' kak printsip stabilizatsii 
mezhnatsional'nykh otnosheniy $\mathrm{v}$ obshchestve [Social justice as a principle of stabilizing interethnic relations in society] // Gumanitarnyye, sotsial'no-ekonomicheskiye i obshchestvennyye nauki [Humanitarian, socio-economic and social sciences]. — 2014. — №11-1. — Pp. 73-77.

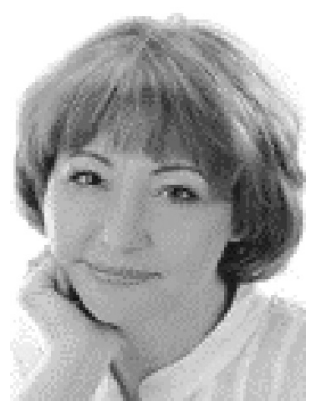

Чернобровкина Наталья Игоревна - кандидат философских наук, доцент, доцент кафедры экономической социологии и регионального управления Института социологии и регионоведения Южного федерального университета. Область научных интересов: регионализация в странах евразийского региона с позиций форм и моделей ее развития в странах Европейского союза, странах Черноморско-Каспийского региона и России. Стаж по специальности - более 25 лет.

Chernobrovkina Natalia Igorevna - Candidate of Philosophical Sciences, Associate Professor, Associate Professor of the Department of Economic Sociology and Regional Management, Institute of Sociology and Regional Studies, Southern Federal University. Research interests: regionalization in the countries of the Eurasian region from the standpoint of the forms and models of its development in the countries of the European Union, the countries of the Black Sea-Caspian region and Russia. Professional experience is more than 25 years.

344006, г. Ростов-на-Дону, ул. Пушкинская, 160 160 Pushkinskaya st., 344006, Rostov-on-Don, Russia E-mail: nichernobrovkina@sfedu.ru 